\title{
Discursos sociales para reproducir la sociedad: Tópica del arte relacional en Latinoamérica*
}

\author{
Bianca Suárez**
}

\author{
Recibido: 3 de abril de 2014, \\ Evaluado: 24 de abril de 2014 \\ Aceptado: 10 de mayo de 2014
}

\section{RESUMEN}

Nicolas Bourriaud propone una discusión en torno a la legibilidad de ciertas expresiones artísticas, en las que la ausencia de un discurso teórico permite descodificar las prácticas sociales que configuran al arte contemporáneo. A estas expresiones interactivas sociales las presenta como formas de una "estética relacional". Para el presente trabajo, utilizaremos como objeto de análisis las expresiones relacionales que utilicen principios de la ciencia y tecnología. A este conjunto de objetos, acciones y fines estéticos nos obligaremos a nombrar temporalmente como AcT o el objeto complejo de arte con ciencia y tecnología en sociedad.

Tekhne o techne es la experiencia de los oficios calificados o del arte, designada por los antiguos griegos como la acción eficaz y se opone a la noción de praxis propuesta por Aristóteles, que es una acción inmanente que lleva en sí misma su propio fin, y está relacionado de manera directa con la poiesis, en tanto actividad conducente a un resultado, la actividad que tiene como objeto un producto distinto de la actividad misma. Lo que percibimos 'yaallí' del 'en Latinoamérica,' es una tensión centrípeta de los conceptualismos artísticos del arte, visiones utópicas e idealistas que procuran una desviación activa y 'fatal' del curso de la historia. Como heteronomías, no parten del desorden formal, ni siquiera de conceptos mínimos que se pueden calificar como críticas

Artículo de revisión, parte de la investigación de Doctorado en Semiotica. Universidad Nacional de Córdoba, Argentina. Cómo citar este artículo: Suárez, B. (2014). Discursos sociales para reproducir la sociedad. Tópica del arte relacional en Latinoamérica. Hallazgos, 11 (22), pp. 67-87

** Doctoranda en Semiótica de la Universidad Nacional de Córdoba, Argentina. Magíster en Antropología Social de la Universidad de los Andes, Colombia. Directora de Investigaciones de la Escuela de Comunicación y Bellas Artes de la Corporación Unificada Nacional de Educación Superior. Email: estrellitaspirit@|yta.tv. Calle 54 No. $35-31$ of. 402. Bogotá, Colombia. 
sociales, deconstructivas o subversivas, sino son principalmente visiones subjetivas de una realidad cotidiana y ordinaria que no todo el mundo ve, pero que al mismo tiempo está fuertemente familiarizada principalmente por los medios masivos. Estas obras de arte activas son expuestas en formas audiovisuales como el videoarte, la música concreta y el circuitbending.

Estas acciones tecnológicas eficaces son hechos que se situarían fuera de la aceptabilidad y la inteligibilidad normales, instituidas por la hegemonía que configuran principalmente las pulsiones del arte más tradicional, y que están directamente en contacto con la lengua y su contexto; es decir, supone fenómenos de significación con las estructuras profundas de los semas, asociados a la realidad de la sociedad latinoamericana. El conjunto de estos tópicos que sirven para desarrollar argumentos son la tópica, ars inveniendi o arte de la invención, y la finalidad de esta parte de la retórica es establecer los contenidos del discurso.

El discurso social, en cuanto todo lo que se publica y es conocido en un estado de sociedad, todo lo que se representa en los medios, es también todo lo que se cuenta, se dice y se comprende. Así pues, es en las operaciones de narrar en las que podemos descubrir un argumento las que son operaciones de puesta en discurso.

La doxa, en los discursos sociales que utilizan las AcT, obliga a establecer un entramado de experimentación o novedad, en cuanto que son lecturas diferentes de lo previsible. Los señuelos de innovación pueden ostentar un potencial totalitario, lo que significa que reduce lo nuevo en experimentación tecnológica, a lo previsible de ser dicho en Latinoamérica como lugar en desarrollo. Lo que se enuncia en la vida social del AcT acusa estrategias por las que sus enunciados reconocen un posicionamiento acorde a políticas culturales, incentivos para proyectos de innovación y desarrollo, y operan según este reconocimiento para obtener beneficios de las políticas culturales estatales. Tal como lo presenta Marc Angenot en 2010, el discurso social como unidad global es la resultante de estrategias múltiples, aunque no aleatorias; presentando así cierta estrechez monosémica hacia la transformación social.

Palabras clave: tópica, argumentación combinatoria, retórica, arte relacional, Latinoamérica, discursos sociales. 


\title{
Social discourses to reproduce society.
}

\section{Some tópica I arguments of relational art in Latin America}

\begin{abstract}
Nicolas Bourriaud proposes a discussion on the readability of certain artistic expressions where the absence of a theoretical discourse can decode the social practices that shape contemporary art. These expressions social interactive ways of presenting them as a "relational aesthetics." For this work we will use AcT to callthe complex object of relational expressions that use principles of science and technology. This set of objects, actions with aesthetic purposes will force us to look in to Latinoamerica society.
\end{abstract}

The latin term tekhne or techne is the experience of the skilled trades or craft, designated by the ancient Greeks as the ' effective action ' and opposes the notion of praxis given by Aristotle, who is an immanent action carries within itself its own end and is directly related to poiesis, while activity leading to a result, the activity aims a product other than the activity itself. What we perceive 'already - there' of 'Latin America' is a centripetal tension from artistic conceptualism of art, utopian visions, idealists who seek an active and 'fatal' deviation from the course of history. As heteronomy, these don't start formal disorder, even minimal concepts that can be classified as social criticism, deconstructive or subversive, but are mainly subjective views of everyday, ordinary reality that not everyone sees, but at the same time is strongly familiar mainly by the mass media. These active works of art are exhibited in audiovisual forms such as video art, concrete music and circuitbending. These effective technological actions are facts that would fall outside the acceptability and normal intelligibility instituted for hegemony primarily set impulses of 
traditional art and come in direct contact with the language and its context, ie, supposed phenomena of significance with deep structures orsemes associated with the reality of Latin American society. All these topics, which serve to develop arguments are tópica 1 , ars inveniendi or art of invention, and its purpose part of the rhetoric, is to establish the content of the speech.

Social discoursesare everything that is published and is known in a state of society, everything is represented in the media, is all that counts, it is said and understood. So, is narrating operations where we can find an argument, are operations into discourse.

The doxa in social discourses in AcT establish a new experimental uses or different readings from the predictable. Lures innovation can boast a potential totalitarian, which means reducing the technologicalexperimentation foreseeable in Latin America, as a place in development. What is stated in the social life of the accused AcT strategies recognize their positioning statements, incentives projects for innovation and development, and operate according such recognition to obtain benefit from state cultural policies. As presented by Marc Angenot in 2010, the social discourse, as global unity, is the result of multiple, but not random strategies, thus presenting somenarrow monosemic towards social transformation.

Keywords: Topical, argumentative combination, rhetorical, relational art, Latin America, social discourses. 


\section{Discursos sociais para reproduzir a sociedade. Tópica da arte relacional na América Latina}

\section{Resumo}

Nicolas Bourriaud propõe uma discussão sobre a legibilidade de certas expressões artísticas, onde a ausência de um discurso teórico deixa decodificar as práticas sociais que configuram a arte contemporânea. A estas expressões interativas sociais as apresenta como formas de uma "estética relacional". Para este trabalho, utilizaremos como objeto de análise as expressões relacionais que utilizem os princípios da ciência e da tecnologia. Para este conjunto de objetos, ações e fins estéticos nos forçar-nos-á a nomear temporariamente como AcT, ou o complexo objeto de Arte com a ciência e tecnologia na sociedade.

Tekhne ou techne é a experiência dos ofícios qualificados ou da arte, que foi designada pelos gregos antigos como a "ação eficaz" e opõe-se à noção de práxis apresentadas por Aristóteles, que é uma ação imanente que carrega dentro de si seu próprio fim e está diretamente relacionada com a poiesis, enquanto a atividade que conduz a um resultado, a atividade que tem como objetivo um produto diferente do que a própria atividade. O que percebemos "já-ali" do "na América Latina" é uma tensão centrípeta dos conceptualismos artísticos da arte, visões utópicas e idealistas que buscam um desvio ativo e 'fatal' do curso da história. Como heteronomías, não começam da desordem formal, até mesmo de conceitos mínimos que se podem qualificar como críticas sociais, deconstrutivas ou subversivas, mas são principalmente visões subjetivas de uma realidade cotidiana e comum que nem todo mundo vê, mas que ao mesmo tempo é fortemente familiarizado 
principalmente pelos meios de comunicação de massa. Estas obras de arte ativas são expostas em formas audiovisuais, tais como o vídeo-arte, a música concreta e o circuitbending.

Estas ações tecnológicas eficazes são fatos que estão fora da aceitabilidade e inteligibilidade normais, instituídas pela hegemonia que configuram principalmente as pulsões da arte mais tradicional, e que estão diretamente em contato com a língua e seu contexto; ou seja, supõe fenômenos de significação com as estruturas profundas dos "semas", associados à realidade da sociedade latinoamericana. O conjunto de todos esses temas, que servem para desenvolver argumentos, são a tópica, ars inveniendi ou arte da invenção, e o propósito desta parte da retórica é estabelecer os conteúdos do discurso.

O discurso social, enquanto que tudo o que é publicado e é conhecido num estado de sociedade, tudo o que é representado nos meios de comunicação, é também tudo o que é dito e é compreendido. É assim então, que é nas operações do narrando onde podemos achar um argumento, são operações de montagem num discurso.

A 'doxa', nos discursos sociais que usam as AcT, forçam-se a estabelecer um quadro para a experimentação ou novidade, no entanto que leituras diferentes do previsível. As iscas de inovação podem-se vangloriar de um totalitário potencial, isto significa que reduz o novo em experimentação tecnológica, ao previsível de ser dito na América Latina como um lugar em desenvolvimento. O que se afirma na vida social da AcT, acusa estratégias pelas que suas declarações reconhecem um posicionamento de acordo com as políticas culturais, incentivos para projetos de inovação e desenvolvimento, e operam de acordo com tal reconhecimento para obter benefícios das políticas culturais do Estado. Segundo tem-lo apresentado Marc Angenot em 2010, o discurso social como unidade global, é o resultado de estratégias múltiplas, embora não aleatorias; apresentando, assim, certa estreiteza monossêmica para a transformação social.

Palavras-chave: Tópica, argumentação combinatória, retórica, arte relacional, Latino América, discursos sociais. 


\section{Situación histórica del arte RELACIONAL EN LATINOAMÉRICA}

La descripción de los discursos sociales concretos, en particular de los discursos manifiestos en el arte latinoamericano reciente, ha puesto en evidencia la complejidad semántica del nivel narrativo. A partir de una representación principalmente pragmática de las transformaciones narrativas, la semiótica ha venido elaborando gradualmente la descripción de los actores, de los actos del lenguaje y de su sentido.

El enunciado, producto de una actividad enunciativa, propone una instancia previa, ausente de la instancia de la enunciación. La operación de selección y combinación, entre las amplias posibilidades que ofrece la gramática narrativa, la instancia enunciativa selecciona la que aparecerá correctamente en el enunciado. Esta selección es una decisión manifiesta que revela una posición ideológica. Así también, la sucesión de las transformaciones narrativas es el resultado de operaciones de combinación. La enunciación en las artes, como toda enunciación, es la instancia de la producción de semiosis. Para lograrlo, la enunciación artística tiene que realizar determinadas operaciones de producción, a partir de la puesta en circulación de contenidos ya asimilados por la cultura, cuyos resultados quedan patentes en el enunciado ${ }^{1}$.

La puesta en discurso del AcT (objeto complejo de las artes aplicadas que hacen uso de ciencia y tecnología) en Latinoamérica se articula con su situación histórica cronotópica

1 Por lo tanto, leer el contenido de una obra de arte, es así mismo una interpretación de otras obras relacionadas en el enunciado. particular, caracterizada por dar una importancia mayor a las relaciones que se establecen, entre y con los agentes, a quienes se dirige la dinámica artística, que a objeto artístico en sí, es inmanente de significación. Es así, como las AcT tienen una fuerza perlocutiva, orientada hacia destinatarios cuyo habitus dóxico identitario lleva consigo una permeabilidad particular a estas influencias, una capacidad de disfrutarlas y renovar su placer por este tipo de arte interactivo y complejo. La intención por probar la resistencia del AcT al interior del campo social global, antes que expandir sus límites a un problema por el objeto artístico en sí, se caracteriza también por una tópica discursiva de disidencia, que ahora sale del cubo blanco del museo y se emplaza en contextos urbanos utilizando ciertos discursos de revolución, a poner en circulación en la sociedad de incidencia y así a visibilizar contenidos invisibles como la "liberación", "hiperorgânicos" y "el sur".

En su libro Conceptualismos, el Uruguayo Luis Camnitzer muestra que el arte en Latinoamérica jugó un papel diferente al que tuvo en los años 60 y 70 en Europa y Estados Unidos, en el que los artistas conceptuales buscaron, principalmente, desafiar la primacía del objeto de arte y las instituciones de arte, así como la comercialización del mismo. El argentino Roberto Jacoby y otros artistas latinoamericanos se volvieron hacia el conceptualismo como vehículo para cuestionar y argumentar radicalmente la propia naturaleza del arte en sí mismo, así como el papel del arte en respuesta a las necesidades y crisis sociales en relación con la política, la poesía y la pedagogía; evidente en la red Conceptualismos del Sur (Museo Reina Sofía, 2011). Debido a este conjunto de contenidos 
distintivo, el arte debe ser visto y entendido por derecho propio, ya que se sustenta en función de sí mismo, no como un derivado de modelos euro-americanos, "superando las dinámicas coloniales de centro-periferia" (Autor, 2011, p. 130).

La colocación de la evolución del 'conceptualismo' o los 'conceptualismos del sur' dentro de la historia de América Latina explora esta tópica de estrategia argumentativa, en lugar de un simple estilo de la cultura latinoamericana. Camnitzer y Jacoby encuentran las raíces del conceptualismo a principios del siglo XIX en la obra de Simón Rodríguez, tutor de Simón Bolívar. Esta corriente continúa con Camnitzer hasta el punto donde el arte se cruza en la política, al igual que con el grupo argentino Tucumán Arde en el año 1968 (Longoni 2008), y con el movimiento Tupamaro en Uruguay durante la década de 1960 y principios de 1970. Camnitzer concluye la investigación de cómo, a partir de 1970, las manifestaciones conceptualistas volvieron al redil de arte más convencional, y se describen algunas de las consecuencias que siguieron cuando el arte pasó a ser una herramienta política para convertirse en lo que se conoce como "arte político", hasta la "cultura libre" manifiesta en otras formas de AcT en países como Venezuela, Uruguay, Perú, Brasil y Colombia.

\section{MAQUiNARIAS QUE TRANSFORMAN EL ENTORNO HUMANO}

Como hemos visto, los artistas 'comprometidos' ${ }^{2}$ latinoamericanos razonan de manera

2 Las discusiones sobre estética y teoría del arte de fines del S. XX, se caracterizan por hallar salidas al exhausto debate entre partidarios del arte puro, abstraído de la realidad y del arte comprometido. "El autoconocimiento — dice Hans G. Gadamer sobre el artista crítica, tomando en cuenta los progresos tecnológicos hacia la realización de un cambio social acorde con su contexto. García Canclini (1993, pp. 3-12) explica estos procesos al elaborar el modelo de teorías de la modernidad ilustrada, refiriéndose a las definiciones sobre arte y la literatura modernos, en el que la modernización se construyó en un proceso de emancipación y liberación que se refiere al individuo, la secularización y la racionalización de la interacción social; luego, un proceso de expansión incluye como meta el descubrimiento científico, el desarrollo industrial y el capitalista. Este razonamiento hacia la modernidad del individuo tiene por objetivo el incremento del lucro, la individualización. El proceso posterior de renovación de estos objetivos partió de la necesidad de reformular signos de distinción que el consumo y la desigualdad desgastaron.

García Canclini expone en este itinerario hacia la democratización, el papel de la educación, las artes y la comunicación de los saberes a fin de lograr la racionalidad y la moralidad dentro del cuerpo social. El artista que aspira a una transformación social debe utilizar con conciencia la tecnología, para transformar la realidad y así diseñar el tipo de efecto que tendrá en el entramado urbano humano. Es aquí donde el enunciado manifiesta que el arte cumple su función de propaganda, orientada hacia el fin de la

comprometido - no significa un interés en sí opuesto al otro, tiene que ver más exactamente con lo común entre el uno y el otro". El conocimiento de sí no implica el ensimismamiento introspectivo que aísla de los otros o que eleva por encima de ellos. Implica, más bien, el entrar en comunidad con el otro, en una relación de escucha y pertenencia, si seguimos el bello juego de palabras que hace Gadamer entre escuchar - hören-y pertenecer - gehören-. Es por esto que la amistad, para decirlo con el hermeneuta, "[...] conduce al incremento del propio sentimiento de vida y a la confirmación de la propia autocomprensión, como lo implica el concepto virtud -areté-" (1991, p. 403). Estas éticas tienen un fuerte componente político. 
transformación social. En las artes tradicionales y académicas, la pintura, la escultura, en la primera revolución modernista, incluso desde la pintura rupestre, se presentaron los primeros ideogramas de transformación social como designios de futuro. Por su parte, el arte moderno en Latinoamérica exponía al mundo miradas de la vanguardia para Europa, aunque referentes al universo cotidiano de las calles, los carnavales y el hambre.

Antonio Berni, Joaquín Torres García, Tarcila do Amaral, y Xul Solar son referentes ideológicos de universales totalizantes, hacia visiones sociales en búsqueda de mayor eficacia de la industrialización. La máquina como motor de transformación de las ciudades se introduce en la vida cotidiana latinoamericana y se establece como héroe, y en cuanto agente utiliza un lenguaje nuevo que no se desprendió de golpe de la modernidad, sino que se compuso de argumentos antecedentes y diseños prospectivos. La máquina como mito estético apoyó las luchas obreras hacia la imagen de la "revolución fatal"3 como emancipación completa de todos los seres humanos, resultante también del carácter de cohesión retórica propia del género propagandístico, que emigra de la incertidumbre y de lo impreciso.

De esta manera, Marc Angenot interpreta el papel revolucionario de la literatura y las artes, ya que, en efecto y por mencionar sólo un par de ejemplos ilustrativos en el

3 "A más de errores de la ideología, sólo debemos tener la infertilidad. Nuestra intransigencia de pensar que no se puede vencer en la lucha, es vacía". Exigió que, por lo quimérico de la literatura libre en la URSS desempeñe plenamente su papel fundamental de revolución, de lo contrario, dijo, "el riesgo de relleno cráneo involuntario y la creación de un acuerdo revolucionario, tan convencional y engañoso que cualquier otro" le pareció fatal y mortal (Angenot, 2010, pp. 151-156). campo de la literatura latinoamericana, el poeta chileno Vicente Huidobro, defensor entusiasta de la experimentación artística durante el periodo de entreguerras, analiza el punto de vista singular de la máquina, y compone su mitología a partir del horror de la motorización del 'presente' como algo aceptado acríticamentw: "la máquina y sus correlativos son legitimados" sostiene Huidobro. Así también, los artistas Cesar Vallejo y José Carlos Mariategui, influenciados por el pensamiento de izquierda marxista, levantan una postura frente a la ensalsación de la máquina y las políticas de mitologización tecnológica ${ }^{4}$, sostiene Rodrigo Alonso (2011).

En México, en las décadas de los años 10 y 20, lo tecnológico viene a actuar en consecuencia de su revolución; las ideas del artista futurista Filippo Tommaso Marinetti entran en un espacio social particular: el movimiento del Estudiantismo. Se instauran entre poetas que adoptan el cambio tecnológico como un elemento de innovación, y se separan del arte más tradicional incluyendo desarrollos estéticos que el futurismo de derecha difundió. El Estudiantismo, como

4 Alonso comenta que a veces, los europeos y los norteamericanos son un poco distraídos. Pero llama la atención que el artista nigeriano Okwui Enwezor -aunque residente desde hace muchos años en los Estados Unidos-, no se percatara de la impresionante presencia tecnológica que atravesaba estructural y visualmente toda la exposición. Más aún, cuando la crítica señaló que la exhibición parecía un noticiero de CNN desplegado en el espacio, o el cuarto de control de Gran Hermano, el curador se sintió ofendido, pues adujo que los críticos no habían comprendido la radicalidad de su propuesta, y que las imágenes desplegadas en la Documenta 11, por su incorrección política, no podrían haberse mostrado jamás en el marco de un servicio informativo como el de la CNN. En una entrevista periodística, Enwezor se queja "¿Por qué tanta gente la vio [a Documenta 11] superficialmente como algo parecido a la CNN? En efecto, había una relación con la CNN, pero por contraste: era anti CNN, porque no se trataba de una dieta predigerida de noticias e información sino de involucrar al público en un esfuerzo hacia una nueva ética de la mirada y de la representación" (González, 2002). 
movimiento artístico literario, es atravesado por las innovaciones tecnologías más contemporáneas como la radio y estas precedidas por el telégrafo. La oralidad y la transmisión de la palabra, si bien van ligadas a la poesía, sufren una mutua afectación en producciones híbridas, ubicadas en la operación de escuchar más que en la norma propia de la escritura poética. Sus experimentos han influenciado ampliamente en la música concreta, ruidistas, paisajistas sonoros, y así de la forma en que suena el mundo cotidiano, las máquinas, las tormentas y el error.

A partir del futurismo, los poemas empiezan a tener forma y contenidos explosivos, que ocupan no solo la sonoridad del espacio irradiando desde el centro hacia afuera e interviniendo en lugares museísticos, sino también en el espacio público. Luego los productos estéticos del Estudiantismo se disolvieron cuando la revolución mexicana enfrentó el nacionalismo, así también el ruidismo fuerte a comienzos de la estética postpunk se ha ido enredando con síntesis de audio $\mathrm{y}$ video, y otras expresiones y experimentaciones electrónicas que incluyen la transducción de ondas en datos, y así también en sonidos a través de sensores eléctricos.

Involucrar discursos de la ciencia, concretamente las teorías científicas en una función persuasiva, como en los geometrismos del argentino Eduardo Moisset de Espanés, el perceptismo de Raúl Loza y el arte óptico del venezolano Carlos Cruz Diez, diseñaron obras conforme a teorías científicas que utilizaron una serie de líneas de colores que generan planos, los cuales producen realidades materiales y las formas surgen de la intersección de las líneas con determinadas áreas, y según las áreas se define una teoría para el uso adecuado del color, que se encuentra enunciada en un diagrama de color codificado que construye una realidad. La obra de arte óptico, cinético y otras variaciones geométricas, se crea según una investigación y unos métodos objetivos: números y matemáticas que dejan de lado la expresión, la revolución, y se empieza a idear una obra no dependiente del artista o del individuo, que provoca movimientos en el espectador. La obra puede ser reproducible a partir de un esquema técnico que cumple con un diseño o algoritmo, para que cumplan los espectadores sin mayores indicaciones; la obra y el espacio están rediseñadas como un programa de software.

Todas estas imágenes vehementes de lo tecnológico que supera la realidad y sus automatismos forman parte del material persuasivo, así como también expresan una estética inmanente. Los artistas estridentistas, conjugaban el simultaneísmo del cubismo, la irreverencia de Dadá y el aspecto moderno del Futurismo, al tiempo que daban cabida a las expresiones de la cultura popular y de masas del México de los años 20. Su eclecticismo e interdisciplinaridad los llevó a procurar una simbiosis original entre todas las tendencias de la vanguardia, además de desarrollar una dimensión actual y social, derivada de la revolución mexicana. Ahora los murales, especialmente la obra del mexicano David Alfaro Siqueiros, expande las visiones de futuro con una finalidad pedagógica.

En los años 40 el movimiento Madí, como "una utopía aplicada", valora las transformaciones de vanguardias artísticas europeas y las reutiliza, evidenciando así que

525 de marzo de $2012<$ http://revista.escaner.cl/node/1331〉 
ya han incorporado los ideologemas como la antropofagia propuesta por Tarsila do Amaral y emplazándose en una función identitaria. Aparece el neón y esto permite comprender así cómo es posible modelar elementos que difícilmente se habrían concebido modelables, como la luz eléctrica. Se comprende así que se puede hacer algo que antes no se podía, construir con luz en el espacio. Ese espíritu pluridimensional debió enfrentarse a la avalancha de la posvanguardia y al sincretismo amorfo del posmodernismo, con el agravante de que aquel pluralismo no se proponía acceder de forma abierta a la hibridación ni a lo transversal en sus obras según los planteamientos conocidos. Por el contrario, el movimiento Madí propuso también la participación social al proponer la incorporación del espectador en el funcionamiento de la obra, junto a otros elementos como baterías y objetos eléctricos constitutivos de las primeras obras cinéticas; el agua también puede ser moldeada gracias al acrílico y a los motores, tal como puede ser modelada la luz. Se empezaron a diseñar espacios utópicos hidroespaciales, espacios para la vida humana como espacios de flotación, haciendo uso proyectual de conceptos como vida. Por lo tanto, se inició un camino hacia la argumentación biológica y la energía, también usándola como metáfora de un material libre, moldeable e inagotable, con ideas como la fisión atómica, que, a pesar de descomponer una molécula de agua, la obra continúa.

El arte permite hace explícitos y consolidar ideas propias de la ciencia, que en un proceso de hibridación amplía la visión de tecnología aplicada a la vida cotidiana. La semantización de los usos, más allá de los discursos, inseparable de las prácticas, restringida por el medio que enmarca la acción del individuo, es formada en series que determinan un modo de operación. Abraham Palatnik incorporó motores y luces en su obra cinética, con el fin de lograr una descomposición cromática en una pantalla con una tela flexible, la cual se va distorsionando lumínicamente, proyectando volúmenes que se construyen a partir de patrones visuales en un tiempo, y así, en este pliegue, surge la obra en un periodo de tiempo particular.

La identidad de este agente, el tiempo, es parte constitutiva de la doxa de las AcT en un sentido global, entiéndose doxa como el ensamble del todo, más o menos homogéneo, de opiniones (confusas, contrarias o no), los prejuicios populares o presupuestos generalmente aceptados y evaluados positiva o negativamente, en la que se basa toda la comunicación, en principio, salvo tratando precisamente de alejarse de tales como artículos científicos y sobre todo el lenguaje matemático ${ }^{6}$.La doxa de las AcT está situada automáticamente en el mundo de las prácticas significantes, usa el tiempo regulado por relojes, en un universo donde se ve simultáneamente afectado por el presente del espectador al recorrer la obra y por el interactuar con ella, utilizando por primera vez el uso de transferencia de video $^{7}$, un tiempo real que se experimenta en varias capas de tiempo que conservan una memoria acumulativa de todo su pasado - en obras de videoarte, videoperformance, paisajes sonoros u obras de remix - y otros contratos

6 Por lo tanto, el estudio de los fenómenos dóxicos se encuentra en el punto de contacto entre los estudios del discurso, la sociología, la epistemología y la semiótica.

7 Más de 20 años antes de la aparición de software como Skype, Hangout o cualquier otra red de chat, en obras como las del colombiano Andrés Burbano. 
estéticos y plásticos con el uso del concepto futuro. La obra tiene una duración según el deseo de interacción de cada usuario.

Brasil es un país ampliamente industrializado y una potencia económica. El arte tecnológico se desarrolló gracias a la ayuda de la resignificación del arte cinético. El desafío de la articulación de la industrialización de la ciencia y la tecnología con la política y la cultura, impulsada por las diversas mezclas interculturales, no sólo raciales a las que suele limitarse el mestizaje en Brasil, sino también las formas modernas de hibridación, mejor que el sincretismo, fórmula referida casi siempre a las fusiones religiosas o de movimientos simbólicos tradicionales (Angenot, 1984, pp. 7-19). El arte con ciencia, tecnología y sociedad en Brasil se constituye como un espacio conflictivo de interacción de voces, conciencias o representaciones sociales, de las tensiones políticas y futbolísticas dando un resultado híbrido influenciado dialógicamente por la cultura popular, que demuestra un deseo des-colonial.

Por su parte en la Argentina, sincrónicamente, el arte tecnológico fue fuerte en una época donde la producción industrial también lo era, aunque la dictadura destruyó universidades - las desmanteló para erradicar a los comunistas - ; los científicos e intelectuales tuvieron que emigrar del país, y sus expresiones tratan de persuadir movilizando al destinatario, mostrando desapariciones, desplazamientos, migraciones y crisis de representación. Las representaciones de Argentina, Colombia y otras de Latinoamérica cumplen la función no racional de electrizar, embriagar, exaltar, indignar y correlativamente también legitimar la violencia mediatizándola.
Por el contrario, en Brasil, los militares impulsaron la búsqueda científica, lo que desencadenó una investigación en el terreno tecnológico sin des-aceleración. En Venezuela se hacen investigaciones entre cinética, física y óptica, y en esta intersección se construye el color. Carlos Cruz Diez empieza trabajando en investigaciones entre cinética y participación social, donde la obra se piensa conforme a un espectador. Según Cruz, el espectador participará en la obra en un determinado espacio. Por otra parte, Jesús Soto investiga sobre las variaciones lumínicas y cromáticas, sus obras exploran el color como una realidad penetrable, no para configurar un determinado ensamble visual, sino como algo que se expande, que ayuda a percibir el entorno y que puede ser modificado perceptualmente en estas variaciones cromáticas. La cromo-saturación configura ciertos ambientes, y, así, estados - anímicos o de conciencia-, que están codificados en el color como una inmaterialidad que se puede percibir físicamente, mientras que el espectador interactúa con la obra en frente de la proyección. La artista Matilde Díaz también investigó los efectos ópticos del color cuando construyó un espacio e introdujo una luz secuenciada que, al prenderse y apagarse, confrontaba la disposición de los instrumentos. Los artistas comenzaron a experimentar la particularidad de dispositivos tecnológicos como elementos plásticos, propios a ser ejecutados por el espectador, o a ser completados en un principio dialógico con el participante de la obra.

Movilizados por la apropiación de la experimentación, aparece el cinetismo, proponiendo el movimiento como agente. El mendocino Julio Le Parc emigra a París 
para participar del grupo de investigación en arte visual y experimental. Así inicia el trabajo con espejos, motores y planchas metálicas que tienen unos factores lumínicos particulares, y empieza a poner en funcionamiento al espectador. El objeto científico y el espectador, ellos en movimiento, van a producir un impacto en el espacio museográfico. Le Parc propone un espacio donde se atraviesa con luz, y sus objetos son cuestionados por la sociedad de consumo, la sociedad de mercado, y los medios artísticos tradicionales, quienes consideran que el artista no debe trabajar para la sociedad de consumo sino para un tipo particular de la sociedad, desde una postura política convencida. Previamente, el espacio museográfico dependía de un espectador cultivado que conociera una historia de ese medio, o que tuviera cierta disposición frente al arte académico y tradicional de los museos. En el arte cinético no hace falta que el espectador sepa algo sobre la obra, ahora cualquier espectador que pueda percibir y se motive a apretar un botón, no necesita ningún tipo de conocimiento para obtener una experiencia estética; esta experiencia - también tecnológica- está marcada simultáneamente con el doble signo de la esperanza, en la transformación y su trasfondo político, adhiriendo a cualquiera. Encontramos aquí una estética de lo compartible, que confiere un fuerte valor expresivo completamente contrario al arte de los "estetas burgueses" (Angenot, 2010, p. 193), con objetos encriptados a ser leídos solo por otros artistas cultivados.

Los artistas argentinos Marta Minujín, Juan Downy y Roberto Jacobi proponen trabajar con la realidad de los medios de comunicación. Su obra parte de la publicación de una noticia y de cómo esa realidad comienza a existir; ésta empieza cuando el lector cree que eso sucedió. Es la información que circula por esta falsa noticia, como una antropofagia de George Orwell y de Orson Welles, la que necesita convencernos para creer, y se apoya en arrancar espacios de control a la burguesía y predicar otros paradigmas en lugares propios de la hegemonía, y así, se establece la legitimidad de este recurso mediático popularizado, de representaciones falsas de la realidad.

Estas obras de AcT proponen críticas al capitalismo, al consumismo diacrítico, proponen experiencias que llegan al espectador común y no al espectador propio de espacios artísticos. Las AcT sugieren que la obra no debe ilusionar sino presentar realidades concretas. Esta noción evidencia un análisis materialista del universo de los medios, conduce inmediatamente a una aporía, en cuanto transmuta el movimiento del arte en un socialismo que debe buscarse en el anonimato colectivo de los medios masivos, sin que por estar adscritos a tendencias de transformación social, que al estar disimuladas por ideologemas del consumo tecnológico, logren expresiones persuasivas que tienen una naturaleza doctrinaria por su eficacia formal e interactiva.

Muchos artistas de las AcT, pioneros en medios independientes, trabajan con robótica y software libre en Chile, Perú y Uruguay, sus obras son difíciles de detectar. Esta dificultad de acceso a sus obras, indica un nivel deficiente de producción y circulación de contenidos, lo que también implica que estos grupos sociológicos no tenderían a desarrollar lógicas más complejas -no relacionadas con los sistemas de circulación y recepción de los medios masivos o los museos- en 
detrimento de la conservación de nuestra cultura histórica, sino que sus argumentos se van multiplicando con recursos derivados de la oposición al sistema de circulación que ahora conocemos. Faltaría preguntarse cuál es la naturaleza de los matices disidentes, que distinguen al AcT con robótica y software libre. La ausencia de experiencias reconocidas de AcT no permite entablar diálogos con antagonistas que nutran la discusión en este sentido; tal vez su lógica de argumentación y circulación de contenidos sea para protegerse detrás de un retorno mítico a la naturaleza de la cultura, de la misma manera, pero a la inversa, a las sociedades modernas ${ }^{8}$.

A la vez que las AcT usan elementos de reconocimiento identitario como la papa - en obras con ciencia y biología ${ }^{9}$ - o el pixel crudo - estilo 8bits - que manifiesta cierta postura frente a texturas hiperrealistas o en alta definición de los medios dominantes. Por el contrario, su potencial totalitario se encastra en buscar una democracia tecnológicasociocultural, y se legitima encontrando la eficiencia de los materiales y recursos cuando cualquier usuario lo puede disfrutar. Esta intención de usar interfaces, tecnología, ciencia y arte propone una producción discursiva contraria a lo cotidiano y esto evidencia un enfrentamiento a lo privilegiado.

8 Cabe anotar que es en Perú, Uruguay y Chile en donde se han realizado mayores planes del Estado en la promoción de tecnologías para la educación y la información.

9 La obra del maestro Victor Grippo es pionera su Conceptualismo uso la metáfora de papas como almacenes o paquetes de electricidad; su obra tiene impacto en proyectos como el Laboratorio de Arte y Tecnología Chimbalab, conformado por las chilenas Claudia González y Constanza Piña, ambas artistas visuales de la Universidad Arcis de Santiago y Playa de Valparaíso, aunque el proyecto se desarrolló en La Paz, Bolivia.

\section{REMIX, OTRA FORMA DE DIALOGISMO}

Presentadas algunas estructuras características de la retórica de las AcT en Latinoamérica, tomaremos en cuenta la retórica sistemológica fundamental para lograr una visión general de las formas de argumentación, con la ayuda del modelo problemológico de argumentación y el modelo sismológico de argumentación, caracterizado, este último, por el descontento de una retórica holística fundamental. La argumentación, como habíamos mencionado anteriormente, remite a un contexto retórico totalizante, y la referencia a éste pasa a un segundo plano. Con esta división clasificatoria de los tipos de estructuras argumentativas en las AcT, no habrán de estar vinculadas otras definiciones semánticas posteriores. Esta metodología de análisis sirve únicamente como procedimiento hipotético para una caracterización de un estilo de argumentación, de acuerdo con propiedades retóricas típicas, por lo que se abandona la dimensión contextual del análisis del problema en aras de una argumentación orientada, a una dimensión pragmática en primer plano. Los esquemas de argumentación son marcados por procedimientos de solución principalmente, enunciando el posible desarrollo satisfactorio de un problema bajo signos operativos o diagramas, incluso manifiestan algoritmos donde se obtendrá o justificará la solución de problemas, en este caso, por medio de intervenciones artísticas con programas propagandísticos, como topoi del análisis del problema.

Según el grado de diferencia semiótica, existen tres tipos de agrupaciones que tienen relaciones retóricas llamadas topoi, que 
le dan cierto grado de diversidad a los esquemas de solución de problemas; estos grupos son 1) la combinatórica, 2) la preferética, y 3) la diatética.

El collage en las AcT, en cuanto palabra junto a la imagen, en calidad de imagen junto a imagen, es desde hace tiempo un recurso fascinante, que reproduce e impone un gesto icónico a la obra final, y construye algo nuevo a partir de elementos reconocibles. Un collage es el acumulado de todos los enunciados presentes en una unidad, y será la forma más relacionada con la combinatórica aditiva propuesta por Angenot como 'campo tópico'.

El campo tópico, en perspectiva amplia, es el sentimiento emancipador de la población, y dentro de él, realizar obras que liberen la conciencia política. Un claro ejemplo de este estilo es el remix que utiliza un estilo de argumentación combinatórico, ofreciendo partes de videos, seleccionadas de los medios audiovisuales periodísticos, de las ciencias, de las letras, de fragmentos musicales o de partes de películas, y recomponerlas en fragmentos que se repiten oscilatoriamente. Estos fragmentos son llamados loops con fragmentos rítmicos y con un sentido propio. En los remix emerge un nuevo significado a partir de la mixtura de imágenes y sonidos reconocibles.

El desarrollo de la sociedad industrial en su proceso de renovación presenta la necesidad de reformular signos de distinción que el consumo va desgastando. La repetición de fragmentos se convierte en imágenes, paisajes o apenas ritmos; sus contenidos, desvalorados o despreciados, son elevados al estatus retórico de un principio disponible en todo momento e independiente de la situación de decisión, permanecen como ritmo de fondo mientras van enunciando arengas sociales, más allá de la intención original en que fueron emitidos en los medios de comunicación. Entonces, no es el discurso sino repetir ideologemas lo que constituye un instrumental más pormenorizado de análisis, y es ahí donde surge la preocupación por el principio ético como fundamento del dialogismo en Mihail Bajtin. La obra, en este caso, es una actualización del signo por su destino contextual, un metalenguaje en forma de música electrónica, que solo puede evidenciarse en la experiencia que será conocida por connotación en la totalidad de la obra, lo que quiere decir que la sintaxis general de una pieza de remix es resultado derivado de la discusión del problema. Aquí la intersubjetividad no implica a sujetos aislados en proceso de comunicación, por el contrario, el concepto de persona es una compleja estructura dialógica que combina argumentos.

Los campos tópicos en Angenot pueden proporcionar una solución del problema, creando los marcos pragmáticos de referencia para la ulterior argumentación, la cual puede estar fundamentada en el origen de los fragmentos, en la peculiaridad de los enunciados en cuestión (referidas a la capacidad emancipadora de la sociedad), y en las consideraciones tecnológicas generales referidas a la propiedad intelectual de la obra. Independientemente del artista o del creador, la obra hace parte del proceso de la misma liberación de contenidos.

En el remix, el borde o contorno se desvanece y se convierte en textura. Por esto, no se puede realizar una distinción entre el 
contenido de la música, las imágenes con un contenido ideológico, o las palabras sobreimpresas. La experiencia de continuidad es inmanente por su materialidad audiovisual; la creación de textura difunde los elementos de manera que se ofrece una ilusión de homogeneidad, que también puede ser analizada como actos del discurso. Estos actos del conocimiento muestran una consciencia de un repertorio de estilos para abordar un conjunto de reglas determinadas, por la función cognitiva de los discursos y su aprehensión mental, que moldean los discursos como operaciones cognitivas (Angenot, 2005, p. 41). Esto quiere decir que la acción del conocimiento se inicia con una aprehensión del objeto, luego surge el interés consciente por participar de las propiedades que caracterizan la otra de AcT: al interactuar se obtiene un conocimiento por parte del sujeto. Esto significa que se comprende mejor si se participa de comienzo a fin; se actualiza al utilizar fragmentos de noticias o películas que en su relectura cobran nuevo significado, y también requiere y ofrece mayor cultura para su mejor comprensión. Por lo tanto, la obra ofrece una correlación entre el sujeto que quiere conocer y el objeto que deber ser conocido.

Desde luego, el recurso "lo-fi" podría hacer suponer que el estilo tópico de argumentación, oculta un enunciado orientado a demostrar una superficialidad en la forma de usar el recurso tecnológico. Al reciclar tecnología, $\mathrm{o}$ al realizar obras de AcT con plástico u objetos de bajo costo, el objeto en sí mismo goza de una estética en su metamorfosis de objeto tecnológico ayudada por lo digital, y al ser resignificado y explícito en los sobreimpresos que acompañan la obra, donde en el título de ésta se enuncia la propaganda política que sirve a su conflicto central: la propiedad intelectual de cada pedazo desmembrado de la obra original, es reutilizado y recompuesto "con las uñas", con recursividad e ingenio. Estos aspectos estéticos componen el discurso social, en cuanto conjunto de ideas y formas de hablar (fraseología de una comunidad), ofreciendo un reconocimiento de su ordenamiento interno, en el que se manifiesta la hegemonía, o lo que una sociedad determinada, objetiva en textos. Esta hegemonía en el pensamiento cumple funciones sintácticas y pragmáticas, que como signo sintáctico, sirve para acortar la argumentación.

En el presente caso, el remix como operación de construcción discursiva, a partir de la combinación de argumentos, responde a una necesidad de reconocimiento, ya que se distingue en su circulación, la posibilidad de acción de la actividad artística expresiva simplemente; es decir, que es indispensable hacer ver enunciados a partir de los discursos que la movilizan, que también responden a la necesidad de conocer y preservar de una manera económica y sintética, un análisis explicativo mediático de la cultura.

Los topoi tienen tanto la función de fórmulas pragmáticas de solución de problemas como de búsqueda, investigación e innovación. Los textos que acompañan las obras cinéticas del argentino Julio Le Parc son programáticas, esto es hacen propuestas pero sin saber exactamente cuál será el resultado, lo que confirma a las AcT como textos argumentativos orientados a 'realizar' la intención del emisor, con un marcado carácter dialógico. 


\section{SUgERIR COLABORACIÓN Y HACER}

Las características de dialogismo y otras anteriormente mencionadas, también nos remiten a la teoría de los actos de habla de la filosofía del lenguaje, planteada originalmente por John Austin en su obra Cómo hacer cosas con palabras. Estas características nos permiten afirmar que los textos de las AcT son programáticos en cuanto actos ilocucionarios que nos invitan a centrar nuestra atención en el emisor y en sus estados mentales - o intenciones ilocucionarias-, la intención o finalidad concreta - o perlocucionaria-, o los efectos que los enunciados dispuestos en las obras de las AcT producen en el receptor en una determinada circunstancia, logrando que el artista provoque una acción en el usuario. El axioma de que la sociedad se manifiesta organizada y axiologizada, se confirma previendo interacciones y dejando poco margen para la ambigüedad de cómo opera, cómo se prenden o se apagan los motores, o cómo pasar a través de un sensor para activar una luz. Estas formas interactivas programáticas sobre la legibilidad de la realidad, aumentan la dinámica de pensamiento complejizando los conceptualismos en su repetición, aunque disipándose en su profundidad. Los actos ilocutivos de las AcT se comprometen con las necesidades de experimentación en sociedad, al exponer la obra en entornos urbanos, mientras que los efectos de esos actos se evidencian en la retroalimentación del público que activa la obra.

Las inauguraciones o exposiciones son el lugar para impartir su doctrina propagandística como una ley. Workshops y festivales de arte realizados en Latinoamérica difunden gratuitamente estos textos programáticos apoyados en la gestión cultural de secretarías de cultura, institutos, municipalidades, gobernaciones y casas de cultura; o laboratorios de tecnología apoyados por la empresa privada como la Fundación Telefónica.

La intención del hablante en las AcTes posibilitar la interacción como característica inmanente, para estimular la participación ciudadana; es el usuario el que efectúa o evidencia las consecuencias que producen los actos ilocutivos. Aunque las acciones de ambos, artista y participante están retroalimentando el diálogo permanentemente. El participante a la obra se educa, transforma la obra del artista y con sus actos moldea a los demás participantes sobre cómo usar la obra.

Otro aspecto que se ha tenido en cuenta es la intención de realizar obras de colaboración, lo que significa que aunque los derechos morales son del artista, no hay ningunos derechos patrimoniales en juego, lo que propicia reflexionar constantemente sobre las convenciones sobre el intercambio o las contrapartes establecidas. Estos intercambios, en suma, explican la conformación de una sociedad que ahora participa incondicionalmente en el culto del ejercicio del arte, por encima de pasiones políticas, como enuncian los artistas colaboradores de desarrollos de software para el sistema operativo Sugar: "debemos mantenernos apolíticos"10, enuncian.

Esta forma de producción se opone al individualismo, la originalidad es "el resultado artístico que expresa una tercera identidad", la cual es compartida. "La búsqueda de un

10 Conferencia dada por David Farning en el encuentro EduJam el 6 de mayo de 2011. 
modus vivendi en una doxa atomizada y en usa sociedad plural, sirve de legitimación, de contragolpe al resentimiento y al narcisismo de los grupos identitarios" (Angenot, 2005, p. 29).

El segundo axioma complementario de mil variaciones de léxico es que el dominio de lo tecnológico hecho de manera colaborativa no tiene valor económico. Los artistas siguen ayudándose a pesar de estos juicios adversos; "los escritores se valen de aportes ajenos". Y este procedimiento, rarísimo en la antigüedad, es hoy la forma más corriente de producir arte. Numerosos equipos de programadores, músicos, investigadores, periodistas, redactores, fotógrafos, correctores, y confidentes que participan de la producción, conforman colectivos y grupos de producción, uniendo comunidades internacionales de desarrolladores de ideas para transformar la sociedad.

En lo que respecta a la difusión y al mercado de la obra, se manifiesta un tercer axioma donde los artistas no tienen nada que ganar y todo que perder, al compartir sus obras o darlas a conocer por internet, puesto que pierden su valor comercial. Muchos artistas comparten sus producciones, ofreciendo workshops gratuitos en conferencias como Ted $\mathrm{X}^{11}$, sobre cómo produjeron sus resultados, lo que habla de una reforma de costumbres de retribución económica. La producción de obras de manera colaborativa no se refiere a una aberración frente a la adversidad económica, sino a la clave de producción ideológica, donde esta doctrina de

11 Creado en el espiritu de la misión: "las ideas vale la pena difundir", apoyando a los organizadores independientes que quieren crear un evento para motivar ideas y emprendimientos creativos su propia comunidad. compartir se engendra a partir una tendencia por presentar contenidos, con la finalidad de obtener conocimientos a cambio sin un fin económico directo. El compartir de manera colaborativa hace emerger nuevas formas de cultura; dar conocimiento propone que nuevas generaciones comprendan los contenidos, y así, puedan dar conclusiones más complejas. Difundir, compartir y hacer colaborar, cultiva nuevos interactores, que necesitan ser convencidos para creer en el fortalecimiento de una nueva comunidad de mercado.

La tecnología en el arte, como hemos visto, no es un medio neutro. Las AcT y la sociedad se encuentran ligadas al sistema capitalista, a la industrialización, a los sistemas de control que difunden la violencia sacralizando lo político. Las AcT se convierten en instrumentos explicativos de los horrores del pasado. Este proceso retórico de argumentos llenos de historia y análisis; son conceptos impuestos en actos de colaboración, que tienen la función de persuadir a la comunidad de una desviación fatal del curso natural de la historia humana, lo que implica otro modelo de trabajo sin obtener una remuneración económica, aunque sí una acumulación de bienes comunes. Angenot ya anunció que convencer a otro es la excepción y no la regla. De este modo, la reafirmación de compartir realiza una doble crítica a la disciplina artística, al distribuirse según la visión de una nueva economía, y entrar en hacer una empresa global con nuevos límites de lo penable y lo decible, reafirmando el mito de la cultura libre.

Estos discursos sociales, determinantes de la historia de Latinoamérica, conllevan a aquello que además de ser decible, pensable $\mathrm{y}$ argumentable, presenta aquellos modos 
de argumentar como propios desde una instancia social particular, con lógicas distinguibles de otras etapas de la historia. Así mismo, se puede notar cómo en la discusión, los "lamentables" sofismas -oprimido, violento, desaparecido, atrasado- pueden resultar muy útiles para argumentar. Es así como en la vida cotidiana, por ejemplo, no puede contarse con la totalidad de los datos necesarios para realizar una afirmación, aunque es esperable que se tomen atajos en la organización de las ideas, referidos a lo tecnológico, al desarrollo económico y al medio ambiente latinoamericano, y se saquen conclusiones que excedan las proposiciones enunciadas. En este campo de problemáticas aún sin explorar, Angenot descubre la oportunidad para una retórica que analiza casos concretos, cronotopicamente situados, que profundizan en las fracturas de la lógica racional, y que no tenga la intención de dar cuenta de una verdad inmanente, sino que por el contrario teja un entramado discursivo que sí es coherente con esto, que es pensable y enunciable actualmente en el discurso social en Latinoamérica.

\section{REFERENCIAS}

Alonso, R. (2012). Nuevas tendencias en el audiovisual interactivo. La navegación como paradigma narrativo. Colaborarte (pp. 141154). Buenos Aires: La Crujía.

Alonso, R. (2011). Mitología y reflexión crítica. El arte tecnológico y su exhibición. Recuperado de $<$ http://www.icm.arts.cornell.edu/conference_2011/Alonso_Reading.pdf>

Alonso, R. (2002). Elogio de la Low Tech. En A. Burbano, y H. Barragán (Eds.), Hipercubolok. Arte, Ciencia y Tecnología en Contextos Próximos. Bogotá: Universidad de los Andes; Goethe Institut.
Alonso, R. (1998-99). Las Primeras experiencias de videoarte en Argentina. Avances Córdoba, 1 (2).

Ammann, A, y Da porta, E. (2008). Rutas alternativas de la Comunicación. Procesos de significación social, ideología y poder. Córdoba: Ferreira.

Angenot, M. (1984). Bakhtine, sa critique de Saussure et la recherche contemporaime. Etudes françaises, 20(1).

Angenot, M. (2005). Fin de los grandes retos, privatización de la utopía y retórica del resentimiento. Revista Estudios, 17.

Angenot, M. (2010). Interdiscursividades. De hegemonías y disidencias. Córdoba: UNC.

Angenot, M. (2010). El discurso social. Los límites históricos de lo pensable y lo decible. Buenos Aires: Siglo XXI.

Becker, H. (2008). Los mundos del arte. Sociología del trabajo artístico. Bernal: Universidad Nacional de Quilmes.

Bourriaud, N. (2008) Estética relacional. Buenos Aires: Adriana Hidalgo.

Angenot, M. (2007). Postproducción. La cultura como escenario. Modos en que el arte reprograma el mundo contemporáneo. Buenos Aires: Adriana Hidalgo.

Bourdieu, P. (2011). El sentido social del gusto. Elementos para una sociología de la cultura. Buenos Aires: Siglo Veintiuno Editores.

Bourdieu, P. (1992). Las reglas del arte. Génesis y estructura del campo literario. Barcelona: Anagrama.

Bordieu, P. (1987). Looking Back, Ahead. En B. Joerges, y H. Nowotny, Social Studies of Science and Technology. Springer: Netherlands.

Camnitzer, L. (2008). Weltkunst, los sobreentendidos y la mirada arqueológica. En Frente a Frente. Daros Collection: Basel. 
Camnitzer, L (2007) Conceptualism in Latin American Art: Didactics of Liberation. Austin: University of Texas Press.

Canclini, N. (1993) Culturas hibridas. Una modernizacion que atrasa. La cultura bajo la regresión Neoconservadora. México: Casa de las Américas.

Carlon, M., y Scolari, C. (Comp.). (2012). Colaborarte. Medios y artes en la era de la producción colaborativa. Buenos Aires: La Crujía.

Fontanille, J. (1994). Propuesta para una tópica narrativa de carácter antropomorfo. Figuras y estrategias, en torno a una semiótica de lo visual. México: Siglo XXI.

Fraenza, F. (2003). Carácter social de la ciencia y carácter pretérito del arte. En Representación en Ciencia y en Arte. Córdoba: Brujas, Universidad Nacional de Córdoba.

Fraenza, F. (2004). Arte tecnológico y estado crítico del sistema del arte. Córdoba: Universitas. Recuperado el 10 de noviembre de 2011 de <http://www.liminar. com.ar/jornadas04/ponencias/fraenza_ perie.pdf $>$.

Fraenza, F, y Perié, A. (2010) Representando no sólo el arte, sino la vanguardia misma. Recuperado de 7 noviembre de 2011 de $<\mathrm{http}$ ://www.comunidadoffline.com.ar/ articulo.php?id=5>.

Foster, H (2001) El retorno de lo real. La vanguardia a finales de siglo. Madrid: Akal.

Gadamer, H. (1991) Freundschaft und Selbsterkenntnis. Zur Rolle der Freundschaft in der griechischen Ethik. Plato im dialog. Tübingen: Mohr.

Geerz, C. (1976) Art as a Cultural System. MNL. 91 (6), 1473-1499.

Geerz, C. (2003) La interpretación de las culturas. Barcelona: Gedisa.

González, V. (2002) Entrevista a Okwui Enwezor. Página/12.
Greimas, A. (1994). Semiótica figurativa y semiótica plástica. Figuras y estrategias, en torno a una semiótica de lo visual. México: Siglo XXI.

Hernández, G. (1994). Figuras y estrategias, en torno a una semiótica de lo visual. México: Siglo XXI.

Igarza, R. (2008) Nuevos medios. Estrategias de convergencia. Buenos Aires: La Crujía. Igarza, R. (2009). Burbujas de ocio. Nuevas formas de consumo cultural. Buenos Aires: La Crujía.

Jacob, F. (1982). The Possible and the Actual. Seattle: University of Washington Press. Jacoby, R. (2011). Proyecto Bola de Nieve o como crecer barranca abajo en épocas heladas. En El deseo nace del derrumbe. Acciones, conceptos, escritos. Barcelona: Ediciones de la Central/Adriana Hidalgo/Red de conceptualismos del Sur/ Museo Nacional Centro de Arte Reina Sofía.

Latour, B. (2005) Reassembling the social: an introduction to actor-network theory. Nueva York: Oxford University Press.

Le parc, J. (1988). Luz. En AA.VV, Julio Le Parc. Experiencias. 30 años. 1958-1988, Buenos Aires: Secretaría de Cultura.

Le parc, J. (2006). Búsqueda Continua. Recuperado el 20 de julio de 2011 de $<$ http://www.julioLe Parc.org/es/artwork.php?aw_cat_id=7>.

Le parc, J. (2005). Le Parc Lumière. Obras cinéticas de Julio Le Parc. Zürich: Daros Exhibitions.

Longoni, A, y Mentsman, M. (2008). Del Di Tella a Tucumán Arde. Vanguardia artística y política en el '68 argentino. Buenos Aires: Eudeba. Recuperado de <http://encontrooffculturadecidade. wikispaces.com/file/view/Ana+Longoni+Tucuman+Arde.pdf $>$ 
Longoni, A, y Mentsman, M. (2001). Tucumán ardía. Página 12. Recuperado de $<$ http://www.pagina12.com.ar/2001/suple/Libros/01-05/01-05-27/nota4.htm >.

Louvain, P. (2000). Marc Angenot. La Critiqueau servicede la Révolution. Paris: Vrin. Recuperado el 10 de febrero de 2013 de $<$ http://marcangenot.com/wp-content/ uploads/2012/01/Cahier-1.pdf>.

Klinkengerg, J. (1992). El sentido retórico, ensayos de semántica literaria. Murcia: Universidad de Murcia.

Klinkengerg, J. (2003). Claves cognitivas para una solución al problema del iconismo. En De Signis. París: Universidad de Nottingham.

Maturana, H. (1996). Realidad: la búsqueda de la objetividad o la persecución del argumento que obliga. En M. Packman (Comp.), Construcciones de la experiencia humana (pp. 51-138). Barcelona: Gedisa.

Molnar, F. (1997). A Science of vision for visual art. Leonardo, 30 (3), 225-232.

Museo Reina Sofía. (2011). Red Conceptualismos del Sur. Actividades públicas. 10 de septiembre de $2012<$ http://www. museoreinasofia.es/sites/default/files/ memoria/2011/127-164actividades-publicas-2011.pdf $>$

Oliveiras, E. (2010). Arte cinético y neocinetismo. Hitos y nuevas manifestaciones en el siglo XXI. Buenos Aires: Emecé.

Orozco, G. (2000). Travesías y desafíos de la investigación de la recepción en América Latina. Comunicación y Sociedad, 38, 11-36.

Orozco, G. (2002). Mediaciones tecnológicas y des-ordenamientos comunicacionales. Signo y Pensamiento, Medios, mediaciones y tecnologías. Vol. XXI, Bogotá: Javeriana.
Rancière, J. (2005) Sobre políticas estéticas. Contratextos. Barcelona: Museu de Art Contemporani.

Rancière, J. (2008) Le spectateur émancipé. Paris: La Fabriqué.

Rodríguez, P. (2007) Prólogo. El modo de existencia de una filosofía nueva. En G. Simondon, El modo de existencia de los objetos técnicos. Buenos Aires: Prometeo Libros.

Serrano, M. (1977) La mediación social. Madrid: Akal.

Simondon, G. (2007) El modo de existencia de los objetos técnicos. Buenos Aires: Prometeo Libros.

Trilnik, C. (2007) Carlos Trilnik. Bogotá: Pontificia Universidad Javeriana.

Ubeda, M, y Casas, C. (2003) Influencias del arte latinoamericano del siglo XX en Europa y Estados Unidos. Recuperado el 30 de marzo de 2013 de <http://digibug.ugr.es/bitstream/10481/4554/1/ Tesis.pdf $>$.

de Ugarte, D. (2007) De la web 2.0 al fabbing, o el salto que haremos desde la creación comunitaria al bricolaje individual en red. Recuperado de $<$ http://medialab-prado. es/article/de_la_web_20_al_fabbing_o_ el_salto_que_haremos_desde_la_creacion_comunitaria_al_bricolage_individual_en_red $>$.

Valdés, S. (2012). Poéticas de la imagen digital. Cuadernos del Centro de Estudios en Diseño y Comunicación, 41, 203-215.

Villegas, V. (2011). Analogía sobre una brecha creciente (si las papas fueran bombillos Van Gogh y Victor Grippo serían buenos amigos), 2010. Recuperado el 11 de mayo de 2013 de <http://novisibles. org/esp/?p=604>. 